\title{
FABIANO E A BOLANDEIRA COMO MÁQUINA DE CRIAR SUBJETIVIDADES
}

\author{
João Batista Santiago Sobrinho*
}

\begin{abstract}
RESUMO: Este estudo tem como objetivo perscrutar no imaginário de Fabiano, personagem e protagonista do livro Vidas Secas, de Graciliano Ramos, a imagem da "bolandeira", a qual, dentro dos significados que Ihe corresponde, é conhecida como uma "máquina de beneficiar". Esse romance é marcado por intensa emoção social e narra, justamente, a travessia trágica de uma família no deserto da "caatinga" e que, lançados no mundo, transita para lugar nenhum, presa ao circulo vicioso da miséria social que a coisifica e aprisiona.
\end{abstract}

PALAVRAS-CHAVE: Vidas secas. Dispositivo. Trágico.

É pois coerente que a condenação do projeto político prometeico (o homem novo da sociedade emancipada) coincida com a possibilidade técnica, e financeira em última análise, de mudar a especificidade do homem, porque essa mudança não corresponde a nenhum projeto. Sabemos pelos jornais que é possível, que poderemos ter cinco patas ou ser imortais. E isso acontecerá justamente porque não é um projeto. Isso acontecerá no automatismo das coisas.

Alan Badiou.

Vidas Secas, publicado em 1938, é um romance trágico. Antonio Candido afirma que esse romance chega em "plena fase de pré-consciência do subdesenvolvimento" brasileiro e é no romance Vidas Secas que essa fase encontra "alta expressão" (CANDIDO, 1989, p.159). No plano mundial o liberalismo se instaura como força hegemônica. Alan Badiou, para quem o século XX é um século totalitário, em virtude de sua vocação para a Guerra, chama os anos 30 de "os terríveis anos 30" no qual, pelas razões de um colonialismo perverso, a servidão e "o massacre estão presentes" (BADIOU, 2007, p.20). Nesse sentido, ao relatar a travessia de uma família de "infelizes (...) cansados e famintos" (RAMOS, 2002, p.9) em sua luta pela sobrevivência, entretidos sem

\footnotetext{
* Centro Federal de Educação Tecnológica de Minas Gerais, Belo Horizonte, Brasil. Imeio: joaoliter@hotmail.com
}

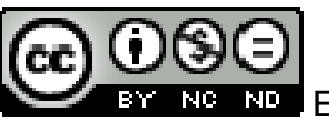

Texto Digital, Florianópolis, v. 10, n. 1, p. 163-173, jan.jul. 2014. ISSNe: 1807-9288 
lugar de chegada ou saída, Vidas Secas compreende bem o século no qual está inserido. Trata-se de um travessia sem fim que representa o circulo vicioso e aporético daqueles que, em virtude da forma como se dá o processo civilizatório, sem os dispositivos que os validem mediante o mundo, vagam em busca do mínimo suficiente para a sobreviverem. Razão pela qual, o livro é sempre dialogicamente atual considerando as características inerentes ao capital e á técnica que o livro retrata, à sua maneira, cujos interesses coincidem mais com as forças que os validam e menos com a condição humana. Em que pese a importância da natureza no romance, passaremos ao largo desse tema, interessanos apenas a "bolandeira" e as possibilidades simbólicas desse significante em sua relação com Fabiano e sua família. O termo ocorre vinte quatro vezes ao longo do romance e sempre ligado ao seu Tomás, personagem que pelas razões do capital, também se torna um andarilho. Dos anos 30 para cá, saímos de uma situação de subdesenvolvimento para uma situação de pais em desenvolvimento. No entanto, estamos longe de mitigar as condições de vida retratadas no romance em análise. Nosso foco coincide mais com a universalidade do romance do que o aspecto regional em virtude mesmo de que a temática abordada implica num totalitarismo que se exerce de forma planetária e, portanto, a que todos estamos sujeitos e que o romance não deixa de retratar.

Vidas Secas começa com o capítulo "Mudança", o qual se configura num vagar constante de Fabiano e sua família no deserto da caatinga em busca de sobrevivência e termina em ritmo mais acelerado e por isso mesmo mais radical, na relação marginal dos personagens com o meio, com o capítulo "Fuga". Conforme Álvaro Lins, "o final do livro é uma retirada, como o princípio fora uma chegada, dentro de uma fatalidade que o romancista sugere ao dizer que eles "dali se afastavam rápidos, como se alguém os tangesse" (LINS apud RAMOS, 2002, p.153). A narrativa se encerra em clima de elipse, com Fabiano sonhando com uma terra: "Uma cidade grande, cheia de pessoas fortes. Os meninos em escolas, aprendendo coisas difíceis e necessárias" (RAMOS, 2002, p.126). No entanto a voz do narrador entremeia-se à voz de Fabiano, chamando-o à realidade trágica em que ele e sua família estão metidos:"Chegariam a uma terra 
desconhecida e civilizada, ficariam presos nela. E o sertão continuaria a mandar gente para lá. O sertão mandaria para a cidade homens fortes, brutos, como Fabiano, sinhá Vitória e os dois meninos". (RAMOS, 2002, p.126).

Um outro livro que tematiza exatamente essa realidade expressa nas últimas palavras do narrador de Vidas Secas, é Cidade de Deus, de Paulo Lins, publicado em 1997, no qual vemos uma espécie de continuidade histórica, para o que afirma o narrador de Vidas Secas no trecho acima. As margens, as favelas, são o destino dos homens "fortes" e "brutos" de que fala Fabiano algumas décadas antes. Otto Maria Carpeaux, em seu texto "Visão de Graciliano Ramos", sintetiza bem o que ocorre na relação entre o sertanejo e a técnica, ao opor um mote recorrente na literatura brasileira, ou seja, a oposição entre o campo e a cidade, entre, digamos, a demora e a velocidade: "O herói de Graciliano Ramos é o sertanejo desarraigado, levado do mundo primitivo, imóvel, para o mundo do movimento" (CARPEAUX apud RAMOS, 1977, 32). Fabiano, metonímia dos "refugos da modernidade", transita de uma "modernidade sólida" para um "modernidade líquida", expressões de Zygmunt Bauman, sem, no entanto, gozar das "benesses" anunciadas nesse trânsito. Se Fabiano não realiza seu sonho na fiç̧ão, outros "Fabianos" no âmbito de uma realidade muito próxima da ficcionalizado por Graciliano Ramos, tragicamente o realizam.

Sônia Brayner, em seu texto "Graciliano e o romance trágico", referindo-se ao homem contemporâneo, afirma:

\footnotetext{
Aprendiz de feiticeiro, o homem contemporâneo desenvolveu técnicas aperfeiçoadas, máquinas destinadas a substituí-lo no próprio trabalho, na ânsia de ganhar o tempo na corrida do século. Agora a mágica começa a tornar-se fantasmagórica. A crise instala-se e a situação limite do homem a braços com sua própria essência leva-o a perder o equilíbrio da lógica de um contexto em que confiara e no qual colocara o endereçamento da vida. (BRAYNER apud RAMOS, 1977, P.204-205)
}

Esse endereçamento da vida de que fala o recorte acima é justamente uma aposta na técnica, esta que os filósofos Heiddeger e Galimbert afirmam ser a essência humana. A técnica para ambos os autores termina por configurar uma 
forma de desabrigar o mundo, posto que é uma forma de saber. Com o termo "técnica" [afirma Galimberti] "entendemos tanto o universo dos meios (as tecnologias), que em seu conjunto compõem o aparato técnico, quanto a racionalidade que preside seu emprego, em termos de funcionalidade e eficiência." (GALIMBERTI, 2001, p.9) (grifos do autor).

Quando digo técnica, estou me referindo também à "máquina de criar subjetividades" a que se refere Agambem, no livro $O$ que é o contemporâneo (2012) que, por sua vez, se antepara em Foucault, Hegel e Heidegger, dentre outros autores, para pensar o processo civilizatório, a técnica e a vontade maquínica que nos provoca a todos. Dispositivo é um conceito que, equivalendose ao que entendemos por técnica,

é um conjunto heterogêneo, linguístico e não-linguístico, que inclui virtualmente qualquer coisa no mesmo título: discursos, instituições, edifícios, leis, medidas de polícia, proposições filosóficas etc. O dispositivo em si mesmo é a rede que se estabelece entre esses elementos (AGAMBEM,2009, p.29)

A bolandeira, neste texto, metonimicamente representa essa "máquina de criar subjetividades" e ou dispositivo, a que se refere Agambem em seu texto "O que é o dispositivo".

De acordo com o dicionário Houaiss, a bolandeira

nos engenhos de açúcar [é uma] grande roda dentada que gira sobre a moenda movimentados as mós [pedras]. Em casa de farinha, roda sobre o eixo vertical que impulsiona o ralador de mandioca. Máquina de beneficiamento de algodão. Edifício onde funciona estes aparelhosetc" (HOUAISS, 2001, p.480).

verbete acima contempla a grande angular a que a expressão "bolandeira" deve abranger, neste texto, cujos significantes, roda, máquina, edifício e aparelhos são todos facilmente assimiláveis à condição de dispositivo. Como uma bolandeira trágica, Fabiano é uma roda dentada que gira sobre e ao entorno do eixo maquínico que, apesar de estar ante seus olhos e ou sobre seus pés, é sempre inalcançável para ele. 
Dessa forma, Vidas Secas é bastante representativo, considerando toda ordem de exclusão a que é submetido Fabiano e sua família pelas forças históricas a que se veem envolvidos, cujo êxodo e ou nomadismo revela a perversidade a que grande parte dos povos do planeta ainda se veem submetidos, mascarados pelos meios tecnológicos e as promessas utópicas que lhes são inerentes, por força sobretudo de um modelo mass midiático niislista que alimenta o imaginário humano por intermédio de uma variedade enorme de "teletelas", para usar uma expressão de George Orwell, retirada do livro 1984.

Naturalmente que Fabiano se reconhece como explorado. O capítulo "Contas" não deixa dúvidas quanto a isso: "pouco a pouco o ferro do proprietário queimava os bichos de Fabiano. E quando não tinha mais nada para vender, o sertanejo endividava-se. Ao chegar a partilha, estava encalacrado, e na hora das contas davam-Ihe uma ninharia" (RAMOS, 2002, p.92). No entanto isso faz parte da imagem paradoxal que se estabelece entre o homem e aquilo que o cerca. De forma alguma, a situação retratada no recorte acima, macula a imagem cerne, a "bolandeira", cuja promessa de felicidade jamais se aplicará à Fabiano e sua família.

É no sentido de um totalitarismo dos dispositivos e ou técnica que, nesta perspectiva, leio Vidas Secas, tendo como referência a "bolandeira", o dispositivo máximo, a engrenagem civilizatória com todo seu aparato, a assombrar Fabiano e que é praticamente um sobrenome em seu imaginário ligado ao letrado seu "Tomás" cujo acréscimo "da bolandeira" soa como um adjetivo. Esse homem, expatrão de Fabiano, é figura exemplar por todos os saberes poderes que encerra aosolhos de Fabiano. Mas que representa, pois, o regime de forças que o explora. A referência a seu Tomás no primeiro capítulo do livro é quase mítica, apenas um nome aliado à "bolandeira" que o qualifica, o que reforça a trágica atração entre Fabiano e a forças que o oprime. No segundo Capítulo, "Fabiano", apesar de elucidar a condição miserável de seu Tomás, que perdera tudo, menos a sabedoria, uma outra passagem reveladora chama atenção, a que revela o saber através do imaginário dos personagens. 
Certamente a sabedoria inspira respeito e impõe-se também como forma de poder. Quando seu Tomás da bolandeira passava, amarelo, sisudo, corcunda, montado num cavalo cego, pé aqui, pé acolá, Fabiano e outros semelhantes descobriam-se (RAMOS, 2002, p.22). Nossa tese não passa pela figura do homem que é ou foi seu Tomás, mas por aquilo que ele representa no imaginário de Fabiano como homem-máquina e as possibilidades dessa comunhão como um estilo de sobrevivência, no qual a "bolandeira" se torna o aspecto mais relevante.

No momento em que se aproximam da cidade, ao fim do romance, Fabiano estremece ante a possibilidade de ter que definitivamente abandonar a vida de vaqueiro e se embrenhar por uma vida diferente da que está acostumado. Sinhá Vitória que deseja ter uma cama como a de seu Tomás da bolandeira, numa imagem síntese do que isso representa na imaginação, sonha: "viver como tinham vivido, numa casinha protegida pela bolandeira de seu Tomás" (RAMOS, 2002, p.120). Ainda que soubessem que, o retorno a essa condição significasse que "estariam sempre assustados, pensando na seca" (RAMOS, 2002, p.120), a imagem da bolandeira como metáfora idílica, paradisíaca, é muito forte, sobretudo como lastro a uma condição de explorados que a bolandeira termina por ofuscar, mas que o diminutivo "casinha" clareia. O pouco com a bolandeira é muito, como paródia de uma frase popular: "o pouco com Deus é muito", parece se aplicar nesse caso em que a bolandeira aparece como o grande outro que os protege.

Num momento agudo de fome, no início do romance, Fabiano se compara à bolandeira, mas antes Fabiano se coisifica numa espécie de gradação da "coisa" para o dispositivo. E, ao equiparar-se à bolandeira, da qual "não se diferençava", Fabiano elimina virtualmente a distância entre aquilo que o caracteriza e o dispositivo de cujo grau de perfeição ele se sente longe: "Pensou na família, sentiu fome. Caminhando, movia-se como coisa, para bem dizer não se diferençava muito da bolandeira de seu Tomás. Agora, deitado, apertava a barriga e batia os dentes. Que fim teria levado a bolandeira de seu Tomás?" (RAMOS, 2002, p.14). 
Maria Rita Kehl, no texto "As máquinas falantes", afirma que a

\begin{abstract}
ciência moderna [que legitima as forças que recai sobre Fabiano] nos ensina a pensar o corpo como coisa, propriedade e encargo do Eu, a quem cabem o zelo e os cuidados capazes de garantir o melhor rendimento, a máxima durabilidade e o maior desfrute possível dos recursos dessa máquina que a um só tempo é a sede da mente e da vida" (KEHL, 2003, p.243).
\end{abstract}

Fabiano, ao se comparar com a bolandeira busca na trágica imagem especular os cuidados que garantiriam a ele e sua família, "o melhor redimento, a máxima durabilidade e maior desfrute possível dos recursos dessa máquina que é seu corpo, a qual ele quer semelhante à bolandeira.

Num mundo no qual se abole as diferenças entre o homem e a máquina, conforme encena em Vidas Secas ressoa razões instrumentais fáusticas que embaçam as diferenças entre o natural e o artificial, em favor do homem-máquina. A síntese revelada na relação de Fabiano com seu espelho, homem-bolandeira, seu Tomás, advém de um processo histórico de valorização do mecânico que se acentua com a visão cartesiana do homem cujos traços afloram vigorosos na tardia industrialização brasileira da década de 30 e não foge ao olhar agudo de Graciliano Ramos. Crítico arguto de toda exploração totalitária, Graciliano se insere numa discussão contemporânea que não escapa, por exemplo, aos olhares de Hermínio Martins, Experimentum humanum (2012), e Paula Sibilia, O homem pós-orgânico: corpo, subjetividade e tecnologias digitais (2006). O sociólogo português, no texto, "Tecnologia, modernidade e política", do qual se utiliza Sibilia quando aborda a relação do homem com a técnica, se refere a duas vertentes de relação com a técnica, a Prometeica e a Fáustica. A tradição prometeica estaria ligada ao uso da técnica com fins humanos "à emancipação da espécie inteira, e em particular das classes mais numerosas e pobres" (MARTINS, 2012, p.36). O romance Vidas Secas deixa entrever, pela forma como o autor o encaminha e termina, que está atento criticamente ao poderio dos dispositivos, mesclando pois, por essa razão, uma visão prometeica e fáustica. 
A tradição fáustica esforça-se por desmascarar os argumentos prometeicos, quer subscrevendo, quer procurando ultrapassar (sem solução clara e inequívoca), o niilismo tecnológico, condição pela qual a técnica não serve qualquer objetivo humano para além de sua própria expressão. (MARTINS, 2012, P.36)

Talvez a vontade de Fabiano de ser como a bolandeira traduza por tudo aquilo que a máquina representa um desejo faustico último de mesclar-se à máquina para finalmente ser a própria máquina e assim concretizar um destino, ao passo que a bolandeira, como dispositivo, se torna todo o parâmetro e medida.

A própria concepção de civilização como prisão existente em Vidas Secas: "chegariam a uma terra civilizada, ficariam presos nela" (RAMOS, 2002, p.126), figura o espaço-tempo paradoxal de um processo civilizatório asfixiante ao modelo de humanismo que se encontra em vias de extinção provocado por um modelo de sofisticação e eficácia no qual não se enquadra o homem que não se encontra à altura da técnica. Razão pela qual o homem deve, então, fazer uma upgrade para ultrapassar sua condição de obsolescência em relação às máquinas e a virtualização da vida.

Apesar da situação crítica de Fabiano, assombrado por uma compaixão que the é inerente, pois ele acredita que seu Tomás é, também, uma vítima da seca: "Seu Tomás fugira também, com a seca, a bolandeira estava parada. E ele, Fabiano, era como a bolandeira. Não sabia porque, mas era" (RAMOS, 2002, p.15). Na frase de Fabiano percebemos uma dialética paradoxal trágica no momento em que ele diz que a "bolandeira estava parada". Admitindo-se como bolandeira, a frase de Fabiano apresenta uma contradição importante. Em sua sapiência matuta, de quem, parafraseando Guimarães Rosa, não sabe, mas desconfia de muita coisa, Fabiano ao se sentir a própria bolandeira, embora ele a veja parada, a coloca em movimento, pois como "armação", e ou "dispositivo", a bolandeira não cessa nunca e exerce, justo nesse momento em que ele se refere a ela como semelhante a ele, sua força máxima, a força da sedução e por isso mesmo da manutenção do poder totalitário que ela representa. Por essa razão comparamos

Texto Digital, Florianópolis, v. 10, n. 1, p. 163-173, jan./jul. 2014. ISSNe: 1807-9288 
a compaixão de Fabiano, nesse momento, em relação ao seu Tomás e à bolandeira, àquilo que Agambem, leitor de Hegel, chama de "religião positiva".

A religião positiva ou histórica compreende um conjunto as crenças, das regras e dos ritos que numa determinada sociedade e num determinado momento histórico são impostos aos indivíduos pelo exterior. "Uma religião positiva”, escreve Hegel, numa passagem que Hyppolite cita, 'implica sentimentos que vêm impressos nas almas por meio de uma coerção e comportamentos que são o resultado de uma relação de comando e obediência e que são cumpridos se um interesse direto"” (AGAMBEM, 2009, p.31).

Essa positividade, que compõe o campo de força elencado por Foucault para visualizar o dispositivo, Hegel a considerava um obstáculo à liberdade humana. Em certa medida, a admiração que Fabiano sente por seu Tomás da bolandeira, ratifica a postura por ele assumida ao longo de sua travessia entre o ódio que ele sente em relação ao patrão que lhe engana nas contas; o soldado amarelo que abusa da autoridade, e a admiração que sente pela bolandeira cuja simbologia o afeta somente de modo positivo. De certa forma a ambiguidade de Fabiano representa a relação que de um modo geral estabelecemos com a técnica que termina por ser um obstáculo à nossa liberdade quando e somente por intermédio dela podemos pensar e nos mover. Nublado pelas forças que o mantém distante de uma razão crítica, Fabiano pergunta "que fim terá levado a bolandeira de seu Tomás?" Sabemos que a aí a pergunta é pelo objeto tecnológico tátil. Mas a pergunta pela bolandeira significa, no imaginário de Fabiano e sua família, como no imaginário em geral, a presença do trabalho maquínico/eficaz e de uma vida "melhor" a que sempre, cada vez mais é associado aos dispositivos técnicos.

Para um outro autor, Umberto Galimberti, no livro Psiche e techne: o homem na idade da técnica (2206), o homem moderno, para além do homem prétecnológico, quando a técnica servia como meio para um fim, se tornou funcionário da técnica ou um mero dispositivo. Para o filósofo italiano, a técnica é o nosso mundo: "A técnica, de fato, não tende a um objetivo, não promove um 
sentido, não abre cenários de salvação, não redime, não desvenda a verdade: a técnica funciona (GALIMBERTI, 2001, p. 8), e, continua o autor, o seu funcionamento se torna planetário.

O fato de Fabiano se sentir como a bolandeira, torna a "verdade" inscrita na fala desse personagem e na abordagem dinâmica e crua do romance extremamente atual, tendo em vista o acirramento das forças então vislumbradas por Graciliano Ramos nesse romance de intensa emoção social.

Assim, tratamos pois, aqui, da delicada rede subliminar que se estabelece entre o homem e a técnica que, antes de mais nada, para usar uma expressão de Heidegger, é uma forma de desencobrir o mundo. Forma que incute uma promessa que a despeito da luzes não se cumprirá, não ao menos para todos, tendo em vista aquilo que a formula e impulsiona, ou seja, reduzir os custos e aumentar os lucros, mas que se revigora numa espécie de tradutor mais simpático do que o desencobrimento técnico representa, ao qual a palavra eficácia encobre e justifica. Para tanto abole dimensões caras à condição humana, por razão meramente instrumentais, como o passado e o futuro, gerando o que chamamos de presentificação da vida, agora sob o aparato e calculo econômico da técnica. É nesse sentido que ela se torna uma "máquina de criar subjetividades", provocando-nos a aceitar sem questionamento seu funcionamento e é por isso, também, que a técnica não é neutra conforme propugna o imaginário locupletado por um pletora de informações que the reforçam o caráter salvífico. De acordo com Galimberti

\footnotetext{
para nos orientar, precisamos antes de tudo acabar com as falsas inocências, com a fábula da técnica neutra, que só oferece meios, cabendo depois aos homens emprega-los para o bem ou para o mal. A técnica não é neutra porque cria um mundo com determinadas características com as quais não podemos deixar de conviver e, vivendo com elas, contrair hábitos que nos transformam obrigatoriamente. (GALIMBERTI, 2006, p.8)
}

Naturalmente que incursões mais profundas poderão ser feitas em relação ao que perscrutamos neste texto, que considero apenas uma provocação introdutória à escritura de Graciliano Ramos na sua relação com a técnica. 
FABIANO AND THE "BOLANDEIRA" AS A MACHINE TO CREATE SUBJECTIVITIES

ABSTRACT: The objective of this work is to probe into Fabiano's imaginative world, the main character on Graciliano Ramos' book VidasSecas, the "bolandeira" image, which, among its several meanings, is known as an "improving machine". This novel is marked by an intense social emotion and it actually narrates the tragic crossing of a family into the "caatinga" desert, which, thrown into the world, transits to nowhere, caught into the vicious circle of social misery that imprisons and reduces it into a mere object.

KEYWORDS: Vidas Secas. Device. "Bolandeira". Tragical.

\section{REFERÊNCIAS}

CANDIDO, Antonio. A educação pela noite \& outros ensaios. São Paulo: Ática, 1989.

AGAMBEM, Georgio. O que é o contemporâneo? e outros ensaios. Chapecó: Argos, 2009.

BADIOU, Alan. O século. São Paulo: Ideias \& Letras, 2007.

BRAYNER, Sonia. In: Graciliano Ramos. Graciliano Ramos e o romance trágico. Rio de Janeiro: Civilização Brasileira, 1977.

CARPEUX, Otto Maria. In: Graciliano Ramos. Visão de Graciliano Ramos. Rio de Janeiro: Civilização Brasileira, 1977.

GALIMBERTI, Umberto. Pisiche e techne: o homem na idade da técnica. São Paulo: Paulus, 2006.

KEHL, Maria Rita. In: NOVAES, Adauto (Org.). O homem máquina: a ciência manipula o corpo. As máquinas falantes. São Paulo: Companhia das Letras, 2003.

MARTINS, Hermínio. Experimentum humanum. Belo Horizonte: Fino Traço, 2012.

RAMOS, Graciliano. Vidas Secas. Rio de Janeiro: Record, 2002.

SIBILIA, Paula. O homem pós-orgânico: corpo subjetividade e tecnologias digitais. Rio de Janeiro: Relume Dumará, 2002. 